\title{
Spares Inventory Optimization Based on System Availability
}

\author{
Wang Rui ${ }^{1, a}$, Qi Chen ${ }^{2, b}$, Tao Wei ${ }^{3, c}$ \\ ${ }^{1}$ Dept. of Communication, Dalian Naval Academy, Dalian 116018, China \\ ${ }^{2}$ Dept. of Information Operation, Dalian Naval Academy, Dalian 116018, China \\ ${ }^{3}$ Naval Academy of Armament, Beijing 10061, China \\ ayuezhiying@yeah.net, ${ }^{b} 438724308 @ q q . c o m,{ }^{c k}$ kissinger-2000@sohu.com
}

Keywords: multi-echelon inventory; spare parts; METRIC; optimization; availability

\begin{abstract}
To the actual problem of the equipment support engineering, the system spare parts are divided into two levels, and based on the METRIC theory, the multi-echelon support evaluation model for system spare parts is established. The multi-echelon system support degree is used as the optimization target while the cost is taken as the restriction, and the margin analysis method is applied to inventory project optimization. In a given example,the optimization result is consistent with the basic principle, which can supply decision assistance for equipment support personal to design a reasonable project.
\end{abstract}

\section{Introduction}

Spare parts are not only the supportable resources for equipment maintenance and emergency settlement, but also the important factors to ensure equipment to be in good shape in peacetime. For the fewer consumed and higher priced spare parts, the multi-echelon inventory distribution management is a reasonable support mode, which can make equipment get higher availability while saving large money. Therefore, multi-echelon supply mode is beneficial to enhance support service level and reduce maintenance expenditure, and now it has been wide applied in military support units. The analysis of multi-echelon inventory systems has a long history, studies on inventory theory are mainly in two aspects, one is establishing inventory model under the different conditions andassumptions, and another is using reasonable method to solve the problem of inventory optimization. In the aspect of inventory model, Andersson \& Melchiors studied the two-echelon inventory model with lost sales ${ }^{[1]}, 2001$; Chiang \& Monahan established the dual-channel supply chain model $^{[2]}$, 2005; Dong \& Lee researched a serial multi-echelon inventory system with time-correlated demand ${ }^{[3]}, 2003$; Mitra analyzed a two-echelon inventory system with returns ${ }^{[4]}$, 2009; Parker \& Kapuscinski present a optimization model for a capacitated two-echelon inventory system $^{[5]}$. In this paper, considering the system spare parts' structure, which is divided into two levels, the multi-echelon support evaluation model for system spare parts is researched.

\section{Description of support process}

According to the different structure level in equipment system, spare parts can be divided into the line replaceable unit and the shop replaceable unit. Supposing that a multi-echelon support institution is composed of one base station, several relay stations and grass roots stations, the supporting cycle is $\mathrm{T}$, all equipments are deployed in grass roots stations. Then, the every support stations' inventory level need to be reasonably determined in order to assuring the equipment availability to satisfy the demands. During the supporting cycle, if there is something wrong with the equipment in grass roots stations, which is caused by some line replaceable unit (LRU) is failure, then, the failed LRU is need to be immediately disassembled to repair. If the grass roots station have this LRU spare part, which can be fetched to replace the failed one, or a shortage of LRU happened once in grass roots. Restricted by the equipment trouble diagnosis device and the capability of repair technology, the grass roots 
station has certain repair probability for the failed LRU. If the failed LRU can not be repaired in grass roots station, the failed one will be sent to relay station to repair, at the same time, applying for one of the LRU spare parts from relay station. The relay station also has certain repair probability for the failed LRU, if the relay station can not repair it, it will be sent to base station to repair, at the same time, applying for one of the LRU spare parts from base station. Because the base station is usually disposed with complete trouble diagnosis device and repair technicians, suppose that the base station can repair all failed LRU.

The reason of the failed LRU is that some one of the shop replaceable unit (SRU) is failed, if the SRU spare part is on hand, it can be installed on the LRU, then, the repair for LRU is complete. There is some certain repair probability for the failed SRU in grass roots stations and relay stations, if the current station can not repair the failed SRU, it will be sent to the upper echelon to repair, at the same time, fetching one of the SRU spare parts from the upper echelon. The process of sending and repair for SRU is the same as LRU. When the repair and supply of the LRU is complete, the problem of spare parts' shortage is solved.

\section{Modeling for multi-echelon support evaluation}

\subsection{Definition of parameters}

Definition of the parameters in this paper is that the subscripting notation $i$ denotes the serial number of SRU $(i=1,2, \ldots, I)$, and the subscripting notation 0 denotes LRU; $j(j=1,2, \ldots, J)$ denotes the serial number of grass roots stations, $k(k=1,2, \ldots, K)$ denotes the serial number of relay stations and 0 denotes base support station. The list of notation used in multi-echelon inventory model is given below.

$m_{0 j}$ : the average annual demand rate for LRU in grass roots station $j$;

$T_{i j}$ : mean time to repair for SRU in grass roots station $j$;

$T_{0 j}$ : mean time to repair for LRU in grass roots station $j$;

$T_{i k}$ : mean time to repair for SRU in relay station $k$;

$T_{0 k}$ : mean time to repair for LRU in relay station $k$;

$T_{i 0}$ : mean time to repair for SRU in the base station;

$T_{00}$ : mean time to repair for LRU in the base station;

$r_{i j}$ : repair probability for the failed SRU in grass roots station $j$;

$r_{0 j}$ : repair probability for the failed LRU in grass roots station $j$;

$r_{i k}$ : repair probability for the failed SRU in relay station $k$;

$r_{0 k}$ : repair probability for the failed LRU in relay station $k$;

$q_{i j}$ : when repairing in grass roots station $j$, the conditional probability for the failed LRU that caused by the $\mathrm{SRU}_{i}$;

$q_{i k}$ : when repairing in relay station $k$, the conditional probability for the failed LRU that caused by the $\mathrm{SRU}_{i}$;

$q_{i 0}$ : when repairing in base station, the conditionalprobability for the failed LRU that caused by the $\mathrm{SRU}_{i}$;

$t_{0 j}$ : mean time of delay that the grass roots station $j$ applies for LRU from relay station $k$;

$t_{i j}$ : mean time of delay that the grass roots station $j$ applies for SRU from relay station $k$;

$t_{0 k}$ : mean time of delay that relay station $k$ applies for LRU from base station;

$t_{i k}$ : mean time of delay that relay station $k$ applies for SRU from base station;

$s_{i j}$ : inventory of SRU in grass roots station $j$;

$s_{0 j}$ : inventory of LRU in grass roots station $j$;

$s_{i k}$ : inventory of SRU in relay station $k$;

$s_{0 k}$ : inventory of LRU in relay station $k$;

$s_{i 0}$ : inventory of SRU in base station;

$s_{00}$ : inventory of LRU in base station;

The computation formula for Expected Back-order $E B O(s)$ is given below 


$$
E B O(s)=\sum_{x=s+1}^{\infty}(x-s) \cdot p_{r}(x)
$$

$\mathrm{VBO}(\mathrm{s})$ is the Variance of Back-order, the expressions for $\mathrm{VBO}(\mathrm{s})$ is given as below

$$
\begin{aligned}
V B O(s)=E\left[B^{2}(s \mid x)\right]-[E B O(s)]^{2} \\
E\left[B^{2}(s \mid x)\right]=\sum_{x=s+1}^{\infty}(x-s)^{2} p_{r}(x)
\end{aligned}
$$

Here $s$ is the inventory of spare parts, $p_{r}(x)$ is the steady probability distribution for the amount of spare parts waited for supply.

During the short observing time, the amount of demand for spares parts approximately obey stable Poisson process, however, as the increase of the observing time, the ratio of expected demand value to variance will gradually go upward. So the amount of demand takes on the characteristics of unstable Poisson process, then, the Poisson distribution can be replaced by negative binomial distribution, and the expressions are shown below.

$$
P(x)=\left(\begin{array}{c}
a+x-1 \\
x
\end{array}\right) b^{x}(1-b)^{a} \quad x=0,1,2 \cdots
$$

$E[X]$ is the mean value and $\operatorname{Var}[X]$ is the variance of negative binomial distribution.

$$
E[X]=a b /(1-b) \quad \operatorname{Var}[X]=a b /(1-b)^{2}
$$

$E B O(s \mid E[X], \operatorname{Var}[X])$ and $\operatorname{VBO}(s \mid E[X], \operatorname{Var}[X])$ respectively denote the negative binomial approximate evaluation for Expected Back-order $E B O(s)$ and the Variance of Back-order $V B O(s)$, if $E[X]$ and $\operatorname{Var}[X]$ are given, the parameters $a$ and $b$ can be calculated, then, the value of negative binomial distribution can be calculated through formula (4).

2.2 Determination of spare parts' demand rate

According to the average annual demand rate of LRU in grass roots stations, the average annual demand rate of LRU and SRU in each support station can be calculated.

For grass roots station $j$, the annual demand rate of $\mathrm{SRU}_{i}$ is related to its demand rate of LRU $m_{0 j}$, repairing probability $r_{i j}$ and the conditional probability $q_{i j}$ that the failed LRU is caused by the $\mathrm{SRU}_{i}$, the computation formula is given below.

$$
m_{i j}=m_{0 j} \cdot r_{0 j} \cdot q_{i j}
$$

For relay station $k$, the annual demand rate of LRU is equal to the sum of LRU applied from the relay station $k$ by all grass roots stations.

$$
m_{0 k}=\sum_{j \in k} m_{0 j}\left(1-r_{0 j}\right)
$$

The annual demand rate of $\mathrm{SRU}_{i}$ for relay station $k$ is equal to the sum of $\mathrm{SRU}_{i}$ applied from the relay station $k$ by all grass roots stations, in addition, add the amount of $\mathrm{SRU}_{i}$ demand when repairing the failed LRU in relay station $k$. The equation is given below.

$$
m_{i k}=\sum_{j \in k} m_{i j}\left(1-r_{i j}\right)+m_{0 k} q_{i k}
$$

Same as the relay station, the annual demand rate of LRU and SRU in base station can be calculated through formula (9) and (10).

$$
\begin{aligned}
& m_{00}=\sum_{k=1}^{K} m_{0 k}\left(1-r_{0 k}\right) \\
& m_{i 0}=\sum_{k=1}^{K} m_{i k}\left(1-r_{i k}\right)+m_{00} q_{i 0}
\end{aligned}
$$

2.3 Determination of the Expected value and Variance of spare parts supply channel

Supply channel of spare parts is composed of two aspects, the one is the number of spare parts that are being repaired, the other is the number of spare parts that are being supplying.

In base station, the proportion of demand rate of $\mathrm{SRU}_{i}$ that caused by the repair for LRU is given below. 


$$
f_{i 0}=m_{00} q_{i 0} / m_{i 0}
$$

The supply channel of LRU for base station is composed of two parts: (1) the amount of LRU that are being repaired when base station has the spare parts of $\mathrm{SRU}_{i}$; (2) the amount of LRU that are being delayed to repair because of the shortage of $\mathrm{SRU}_{i}$. Among the sum back-order of $\mathrm{SRU}_{i}$ in base station, the probability of which that lead to LRU supply delay for relay station obey binomial distribution. So the Expected value and Variance of LRU supply channel in base station can be got through formula (12) and (13).

$$
\begin{aligned}
& E\left[X_{00}\right]=m_{00} T_{00}+\sum_{i=1}^{I} f_{i 0} E B O\left(s_{i 0} \mid m_{i 0} T_{i 0}\right) \\
& \operatorname{Var}\left[X_{00}\right]=m_{00} T_{00}+\sum_{i=1}^{I} f_{i 0}\left(1-f_{i 0}\right) . \\
& \operatorname{EBO}\left(s_{i 0} \mid m_{i 0} T_{i 0}\right)+\sum_{i=1}^{I} f_{i 0}^{2} V B O\left(s_{i 0} \mid m_{i 0} T_{i 0}\right)
\end{aligned}
$$

$f_{i k}$ is the proportion of the amount of $\mathrm{SRU}_{i}$ applied by relay station to the sum demand rate of base station, and the calculation formula is given below.

$$
f_{i k}=m_{i k}\left(1-r_{i k}\right) / m_{i 0}
$$

The supply channel of $\mathrm{SRU}_{i}$ is equal to the sum of the amount of being repaired and sent to repair by relay station, in addition, add the amount of $\mathrm{SRU}_{i}$ that are delayed to supply because the base station has not $\mathrm{SRU}_{i}$ spare parts. The expectation and variance of $\mathrm{SRU}_{i}$ for relay station's supply channel can be calculated through formula (15) and (16).

$$
\begin{aligned}
& E\left[X_{i k}\right]=m_{i k}\left[\left(1-r_{i k}\right) t_{i k}+r_{i k} T_{i k}\right]+f_{i k} \cdot E B O\left(s_{i 0} \mid m_{i 0} T_{i 0}\right) \\
& \operatorname{Var}\left[X_{i k}\right]=m_{i k}\left[\left(1-r_{i k}\right) t_{i k}+r_{i k} T_{i k}\right]+f_{i k} \cdot\left(1-f_{i k}\right) \cdot E B O\left(s_{i 0} \mid m_{i 0} T_{i 0}\right)+f_{i k}^{2} \cdot V B O\left(s_{i 0} \mid m_{i 0} T_{i 0}\right)
\end{aligned}
$$

The supply channel of LRU for relay station is composed of multi parts: (1) the amount of LRU received from base station; (2) the amount of LRU that are delayed to supply because the shortage of LRU occurred in base station; (3) the amount of LRU that are being delayed to repair because of the shortage of $\mathrm{SRU}_{i}$ in relay station. So, the expectation and variance of LRU for relay station's supply channel can be calculated through formula (17) and (18).

$$
\begin{gathered}
\begin{aligned}
& E\left[X_{0 k}\right]= m_{0 k}\left[\left(1-r_{0 k}\right) t_{0 k}+r_{0 k} T_{0 k}\right]+f_{0 k} \cdot E B O\left(s_{00} \mid E\left[X_{00}\right], \operatorname{Var}\left[X_{00}\right]\right)+ \\
& \sum_{i=1}^{I} E B O\left(s_{i k} \mid E\left[X_{i k}\right], \operatorname{Var}\left[X_{i k}\right]\right) \\
& \operatorname{Var}\left[X_{0 k}\right]= m_{0 k}\left[\left(1-r_{0 k}\right) t_{0 k}+r_{0 k} T_{0 k}\right]+f_{0 k}\left(1-f_{0 k}\right) E B O\left(s_{00} \mid E\left[X_{00}\right], \operatorname{Var}\left[X_{00}\right]\right)+ \\
& f_{0 k}^{2} \cdot \operatorname{VBO}\left(s_{00} \mid E\left[X_{00}\right], \operatorname{Var}\left[X_{00}\right]\right)+\sum_{i=1}^{I} \operatorname{VBO}\left(s_{i k} \mid E\left[X_{i k}\right], \operatorname{Var}\left[X_{i k}\right]\right)
\end{aligned}
\end{gathered}
$$

The calculation method of expectation and variance for grass roots station's supply channel is same as that of relay station.

2.4 Project evaluation target

Availability of equipment system is an important evaluation target for integrated logistics support, which means the probability of equipment is in good condition at any given time. The premise of availability for system is that all compositive parts could be in good condition, the availability of LRU for the grass roots station $j$ is shown below.

$$
A_{j}(i)=\left\{1-E B O\left(s_{0 j} \mid E\left[X_{0 j}\right], \operatorname{Var}\left[X_{0 j}\right]\right) /\left(N_{j} Z_{0}\right)\right\}^{Z_{0}}
$$

Then we can define support degree $A_{x}$ to evaluate the effectiveness of the multi-echelon support system, $A_{x}$ reflects the proportion of the amount of available equipments to the sum.

$$
A_{x}=\sum_{j=1}^{J}\left(N_{j} A_{j} / \sum_{j=1}^{J} N_{j}\right)
$$




\section{Inventory optimization model and the optimization design}

3.1 spare parts inventory optimization model

The inventory optimization model can be described that when multi-echelon support effectiveness $A_{x}$ reach the required target, minimized the cost of spare parts. Define $s_{i, j}$ is the inventory of the $i^{\text {th }}$ spare part in the $j^{t h}$ station, $C_{i}$ is the cost of the $i^{t h}$ spare part. The optimization model is given below.

$\begin{cases}\min & \sum_{j} \sum_{i} C_{i} s_{i, j} \\ \text { s.t. } & A_{x}=\sum_{j=1}^{J}\left(N_{j} A_{j} / \sum_{j=1}^{J} N_{j}\right) \geq A_{m}\end{cases}$

3.2 Optimization method

Step1: initialize the inventory of different spare parts, set the variable $s_{i, j}=0$.

Step2: execute calculation cycle, during the cycle process of every time, calculate the margin value $\delta_{i, j}\left(s_{i, j}\right)$, which can be got from the computation formula (27).

$\delta_{i, j}\left(s_{i, j}\right)=\left[A_{x}\left(s_{i, j}+1\right)-A_{x}\left(s_{i, j}\right)\right] / C_{i}$

Step3: when the margin value $\delta_{i, j}\left(s_{i, j}\right)$ is calculated, determine the maximum $\delta_{i, j}\left(s_{i, j}\right)$ and add 1 to the corresponding spare part inventory.

Step4: according to the inventory $s_{i, j}$, compute the multi-echelon support degree $A_{x}$ and judge it whether reach the required target, if $A_{x} \geq A_{e}$, calculation cycle is end, or enter the step 2.

\section{Analysis of the given example}

Suppose there is a multi-echelon supply and repair system, which is composed of a base station $\left(\mathrm{H}_{0}\right)$, two relay stations $\left(\mathrm{R}_{1}, \mathrm{R}_{2}\right)$ and multi grass roots stations $\left(\mathrm{J}_{1}, \mathrm{~J}_{2}, \mathrm{~J}_{3}\right)$, to supply spare parts and repair for equipment deployed in grass roots field. The amount $\left(N_{j}\right)$ of this equipment deployed in the three grass roots units are 30, 25 and 20 respectively.

The parameters of equipment system's LRU are shown in table 1. The subscripting notation $j$ denotes the grass roots supply and repair stations, $k$ denotes the relay stations and 0 denotes the base station. All of the time parameters are measured by year, and the cost of spare parts are measure by ten thousand dollars. The number $(Z)$ of LRU equipped in equipment system is 2,2 and 3 respectively.

Table 1 The spare parts' parameter of line replaceable unit(LRU)

\begin{tabular}{cccccccccc}
\hline \multirow{2}{*}{$\begin{array}{c}\text { Spare } \\
\text { part }\end{array}$} & \multicolumn{3}{c}{$\begin{array}{c}\text { annual demand } \\
\text { rate }\end{array}$} & \multicolumn{3}{c}{$\begin{array}{c}\text { mean time } \\
\text { to repair(year) }\end{array}$} & \multicolumn{2}{c}{$\begin{array}{c}\text { repair } \\
\text { probability }\end{array}$} & Cost \\
\cline { 2 - 10 } & $m_{0 j 1}$ & $m_{0 j 2}$ & $m_{0 j 3}$ & $T_{0 j}$ & $T_{0 k}$ & $T_{00}$ & $r_{0 j}$ & $r_{0 k}$ & $C_{0}$ \\
\hline LRU1 & 46.4 & 41.4 & 39.7 & 0.0164 & 0.0247 & 0.0329 & 0.24 & 0.53 & $\$ 53,400$ \\
LRU2 & 46.4 & 39.8 & 30.4 & 0.0192 & 0.0219 & 0.0301 & 0.28 & 0.49 & $\$ 78,800$ \\
LRU3 & 47.7 & 43.4 & 41.7 & 0.0192 & 0.0219 & 0.0356 & 0.22 & 0.61 & $\$ 92,300$ \\
\hline
\end{tabular}

Suppose the period of support is one year, the superior require the multi-echelon support degree value $A_{x}$ is higher than 0.98 . Through margin analysis method, after the computer program experienced 59 times of calculation, the optimal inventory of different supply stations is got, which shown in the table 2.

Table 2 The optimal inventory project of system spare parts

\begin{tabular}{cccccccccc}
\hline \multirow{2}{*}{$\begin{array}{c}\text { support } \\
\text { station }\end{array}$} & \multicolumn{7}{c}{ spare parts of equipment system } \\
\cline { 2 - 10 } & $\mathrm{LRU}_{1}$ & $\mathrm{LRU}_{2}$ & $\mathrm{LRU}_{3}$ & $\mathrm{SRU}_{11}$ & $\mathrm{SRU}_{12}$ & $\mathrm{SRU}_{21}$ & $\mathrm{SRU}_{22}$ & $\mathrm{SRU}_{31}$ & $\mathrm{SRU}_{32}$ \\
\hline $\mathrm{H}_{0}$ & 1 & 1 & 1 & 2 & 3 & 2 & 3 & 2 & 3 \\
$\mathrm{R}_{1}$ & 0 & 0 & 0 & 1 & 1 & 1 & 1 & 1 & 1
\end{tabular}




\begin{tabular}{cccccccccc}
$\mathrm{R}_{2}$ & 2 & 2 & 2 & 2 & 2 & 1 & 2 & 2 & 1 \\
$\mathrm{~J}_{1}$ & 3 & 2 & 2 & 0 & 0 & 0 & 1 & 0 & 0 \\
$\mathrm{~J}_{2}$ & 3 & 2 & 1 & 0 & 0 & 0 & 1 & 0 & 0 \\
$\mathrm{~J}_{3}$ & 2 & 1 & 1 & 0 & 0 & 0 & 1 & 0 & 0 \\
\hline
\end{tabular}

If execute the inventory project shown in table 3 , we can get that the availability of equipments deployed in grass roots units during support period, which are $A_{j 1}=0.9823, A_{j 2}=0.9858, A_{j 3}=0.9718$ respectively, the multi-echelon system support degree $A_{x}=0.9807$, and the support cost is 22,564 thousand dollars.

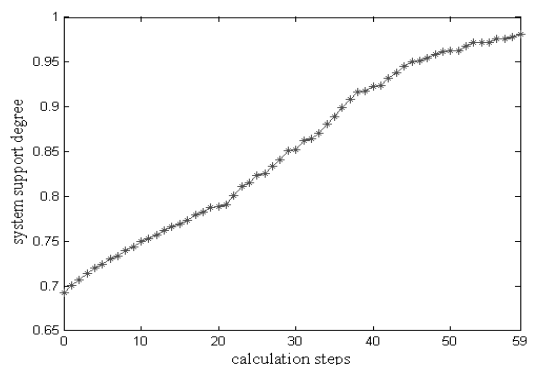

Fig.3 The variability curve of system support degre

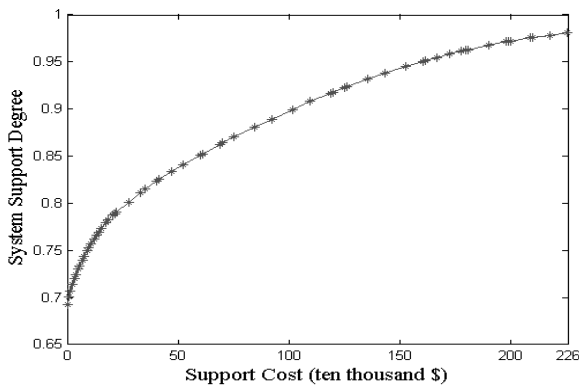

Fig.4 The curve of system support degree vs. cost

\section{Conclusion}

In this paper, we focus on the actual problem of the equipment support engineering. Considering the structure level of system spare parts, and based on the METRIC theory, the multi-echelon inventory optimization model for system spare parts is established. The multi-echelon system support degree is used as the optimization target while the cost is taken as the restriction, and the margin analysis method is applied to inventory project optimization. In a given example, the optimal inventory project is got. According to the optimization result, we get the general principle of spare parts disposition and analyze the influencing factors for spare parts inventory. The result is consistent with the disposition principle under the multi-echelon support pattern, compared to empiricism, this optimization method can save large amount of support cost under the condition of reaching the required target, which can supply decision assistance for equipment support personal to design a reasonable project.

\section{Acknowledgement}

Fund project: The Scientific development fund project supported by Dalian naval academy(20140924)

\section{References}

[1] Andersson J, Melchiors P. A two-echelon inventory model with lost sales[J]. International Journal of Production Economics, 2001, 69(3): 307-315.

[2] Chiang W K, Monahan G E. Managing inventories in a two-echelon dual-channel supply chain[J]. European Journal of Operational Research, 2005, 162(2): 325-341

[3] Dong L, Lee H L. Optimal policies and approximations for a serial multi-echelon inventory system with time-correlated demand[J]. Operations Research, 2003, 51(6): 969-980.

[4] Mitra S. Analysis of a two-echelon inventory system with returns[J]. Omega, 2009, 37(1): 106-115.

[5] Parker R P, Kapuscinski R. Optimal policies for a capacitated two-echelon inventory system[J]. Operations Research, 2004, 52(5): 739-755. 